\title{
A STUDY OF CLINICAL, SONOLOGICAL AND HISTOPATHOLOGICAL CORRELATION OF OVARIAN TUMOURS
}

\author{
S. Valarmathy1, J. Josephine Hema²
}

${ }^{1}$ Associate Professor, Department of Obstetrics and Gynaecology, Sivagangai Medical College, Sivagangai, Tamilnadu, India. ${ }^{2}$ Assistant Professor, Department of Obstetrics and Gynaecology, Madurai Medical College, Madurai, Tamilnadu, India.

\section{ABSTRACT}

\section{BACKGROUND}

Ovarian cancer is the second most common of all gynaecological cancers and accounts for 10-15\% of gynaecological malignancies in developing countries including India. Of all gynaecological cancers, ovarian malignancies represent the greatest clinical challenge because of greater range and variety of tumours with uncertain origin with no known premalignant lesion and variability in the rate of disease progression. Around $70 \%$ of patients with ovarian tumours are diagnosed only at advanced stages due to unavailability of effective screening methods, and lack of specific clinical presentations at early stage of the disease. In premenopausal women $7 \%$ of tumours are frankly malignant, while in postmenopausal women $30 \%$ are malignant. Sonography is considered to be the investigation of choice for the evaluation of ovarian tumours due of its high sensitivity, acceptability and low cost. Morphology indexing is an inexpensive and accurate method in differentiating benign ovarian tumours and malignant ovarian tumours and can be used as an effective tool to plan the management of ovarian tumours. The use of Doppler flow studies along with this morphological indexing have not shown to improve the diagnostic accuracy of morphological indexing.

The objectives of this study are

1. to analyse the sensitivity and specificity of a morphological scoring system in differentiating benign and malignant tumours of the ovary and

2. to study the epidemiology of ovarian tumours.

\section{MATERIALS AND METHODS}

136 patients with an ovarian tumour confirmed by transabdominal ultrasound examination were evaluated during this study period. Transabdominal sonography was performed on all patients using a 3.5-5 MHz transducer. Morphology indexing was performed using volume of tumour and morphologic features of the tumour. The ovary was measured in all its three dimensions and the volume of the ovary was calculated with the use of ellipsoid formula (length $\mathrm{x}$ width $\mathrm{x}$ height $\mathrm{x}$ 0.523). Morphological features include papillary projections, solid areas, echogenicity, presence of septum and the presence or absence of free fluid in the extratumoral space. A score from 0-5 was assigned for each of the component. A total score ranging from 0 to 10 for every tumour. Following morphology indexing, each tumour was surgically removed and was histologically classified according to the WHO system of classifying ovarian tumours.

\section{RESULTS}

Of the 136 ovarian tumours, 92 cases were benign (67.6\%), 3 were borderline (2.2\%) and 41 were malignant (30.2\%). The mean age for benign tumours was 36.7, borderline tumours was 49.7 and malignant tumours was 48.1 respectively. Benign tumours were common in $2^{\text {nd }}$ parity women and malignant tumours were common in women with parity 4 and above. The most common presenting feature in both benign and malignant ovarian tumours was pain abdomen with an incidence of $84.7 \%$ and $82.9 \%$ respectively. Most benign tumours were cystic in consistency (93.4\%) and malignant tumours were hard in consistency (40.5\%) and around $23.8 \%$ of malignant tumours have a variable consistency. Most ovarian tumours were unilateral $(80.9 \%) .92 .3 \%$ of benign tumours were unilateral and $53.6 \%$ of malignant tumours were unilateral. Based on the tumour volume by ultrasound, most benign tumours have a score of $\leq 4$ and most of the malignant tumours have a score of $>4$. Based on the tumour structures by ultrasound, most benign tumours have a structural score of $<2$ and most malignant tumours have a structural score of $>3$. Based on morphological score which includes both volume score and structural score, most of the benign tumours have a score of $<5$ and score of $>5$ suggests malignancy. In the present study, epithelial tumours (117) were the most common ovarian tumours followed by germ cell tumours (11).

\section{CONCLUSION}

Morphological scoring system is helpful in identifying women with ovarian tumours who are at risk for malignancy. Morphological scoring system also effectively decreases the need for unwanted surgery in benign ovarian tumour.

\section{KEY WORDS}

Ovarian Tumour, Morphological Scoring, Benign, Malignant.

HOW TO CITE THIS ARTICLE: Valarmathy S, Hema JJ. A study of clinical, sonological and histopathological correlation of ovarian tumours. J. Evolution Med. Dent. Sci. 2018;7(30):3405-3408, DOI: 10.14260/jemds/2018/768

'Financial or Other Competing Interest': None.

Submission 11-09-2017, Peer Review 04-07-2018,

Acceptance 11-07-2018, Published 23-07-2018.

Corresponding Author:

Dr. J. Josephine Hema,

DF4, Vanaj Agrini Apartments,

Andalpuram, Madurai-3, Tamilnadu, India.

E-mail: josehemaa31@gmail.com

DOI: $10.14260 /$ jemds $/ 2018 / 768$

\section{BACKGROUND}

Ovarian cancer is the second most common of all gynaecological cancers and accounts for $10 \%-15 \%$ of gynaecological malignancies in developing countries including India. Of all gynaecological cancers, ovarian malignancies represent the greatest clinical challenge because of greater range and variety of tumours with uncertain origin with no known premalignant lesion and variability in the rate of disease progression. ${ }^{1}$ Around $70 \%$ of 
patients with ovarian tumours are diagnosed only at advanced stages due to unavailability of effective screening method and lack of specific clinical presentations at early stage of the disease. In premenopausal women $7 \%$ of tumours are frankly malignant, while in postmenopausal women $30 \%$ are malignant. Sonography is considered to be the investigation of choice for the evaluation of ovarian tumours due of its high sensitivity, acceptability and low cost. The morphology indexing is an inexpensive and accurate method in differentiating benign ovarian tumours and malignant ovarian tumours can be used as an effective tool to plan the management of ovarian tumours. ${ }^{2}$ The use of Doppler flow studies along with this morphological indexing have not shown to improve the diagnostic accuracy of morphological indexing. ${ }^{3}$

\section{MATERIALS AND METHODS}

This is a descriptive study conducted in Department of Obstetrics and Gynaecology, in Govt. Rajaji Hospital, Madurai. The study group includes patients who were admitted with an ovarian tumour confirmed by transabdominal ultrasound examination. 136 patients were evaluated during this study period. A standard proforma was used for collection of data. The patients underwent general physical, systemic, per speculum, per vaginal and per rectal examinations. Transabdominal sonography was performed on all patients using a 3.5-5 MHz transducer. The ovary was measured in all its three dimensions and the volume of the ovary was calculated with the use of the ellipsoid formula (Length $x$ Width $x$ Height $x$ 0.523). Morphological features including papillary projections, solid areas, echogenicity, presence of septum, presence or absence of free fluid in the extratumoral space. Morphology indexing was performed using both the volume of tumour and morphologic features. A score from 0 5 was assigned for each of the component. A total score ranging from 0 to 10 for every tumour. Following morphology indexing, each tumour was surgically removed and were histologically classified according to the WHO system of classifying ovarian tumours. The information collected regarding all the selected cases were recorded in a master chart. Data analysis was done with help of computer using Epidemiological Information Package. Sensitivity, specificity, accuracy, positive predictive values and negative predictive values were calculated.

\begin{tabular}{|c|c|c|}
\hline \hline 0 & $<10 \mathrm{~cm}^{3}$ \\
\hline 1 & $10-50 \mathrm{~cm}^{3}$ \\
\hline 2 & $>50-100 \mathrm{~cm}^{3}$ \\
\hline 3 & $>100-200 \mathrm{~cm}^{3}$ \\
\hline 4 & $>200-500 \mathrm{~cm}^{3}$ \\
\hline 5 & $>500 \mathrm{~cm}^{3}$ & \\
\hline
\end{tabular}

\section{RESULTS}

Of the 136 ovarian tumours 92 cases were benign (67.6\%), 3 were borderline (2.2\%) and 41 were malignant (30.2\%) based on histopathological examination.

The mean age was 40.5 years (range, 13-85 years). 60 patients belonged to the age group of 40 years or older and 76 patients were less than 40 years of age. The mean age for benign tumours was 36.7, borderline tumours was 49.7 and malignant tumours was 48.1. $P$ value (0.0001) was significant.

Ovarian tumours were common in multipara of 2, which is considered as statistically significant. Benign tumours were common in $2^{\text {nd }}$ parity women and malignant tumours were common in women with parity 4 and above constituting 33\% and $35.7 \%$ respectively. Incidence of benign tumours in nulliparous women was $22 \%$ and malignant tumours were $14.3 \%$. There were 5 cases $(5.4 \%)$ of ovarian tumours complicating pregnancy.

There was more than one mode of presentation in many cases. The most common presenting features in both benign and malignant ovarian tumours were pain abdomen with an incidence of $84.7 \%$ and $82.9 \%$ respectively.

Most benign tumours were cystic in consistency (93.4\%) and malignant tumours were hard in consistency (40.5\%) and around $23.8 \%$ of malignant tumours have a variable consistency.

Most ovarian tumours were unilateral (80.9\%). 92.3\% of benign tumours were unilateral and $53.6 \%$ of malignant tumours were unilateral.

Based on the tumour volume by ultrasound, most benign tumours have a score of $\leq 4$ and most of the malignant tumours are more having a score of $>4$.

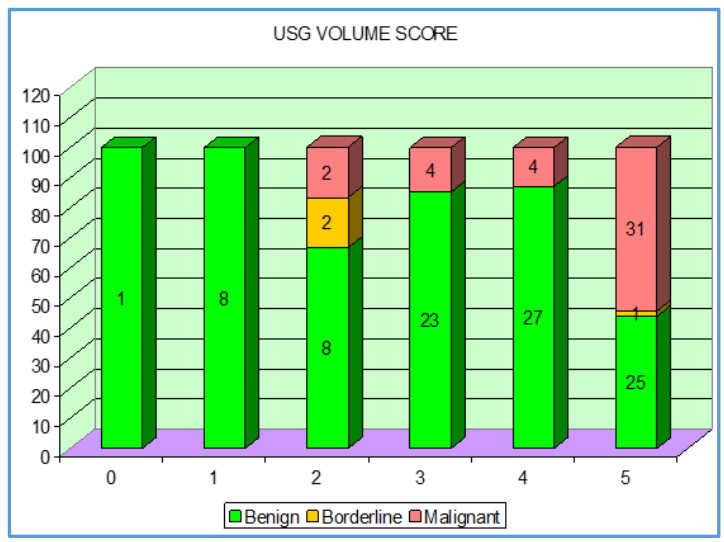

Based on the tumour structures by ultrasound, most benign tumours have a structural score $<2$ and most malignant tumours have a structural score $>3$.

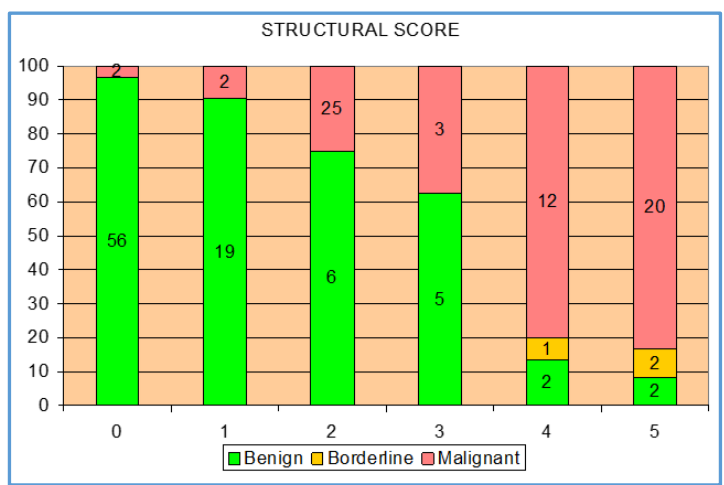


Based on morphological score which includes both volume score and structural score, most of the benign tumours have a score of $<5$ and score of $>5$ suggests malignancy.

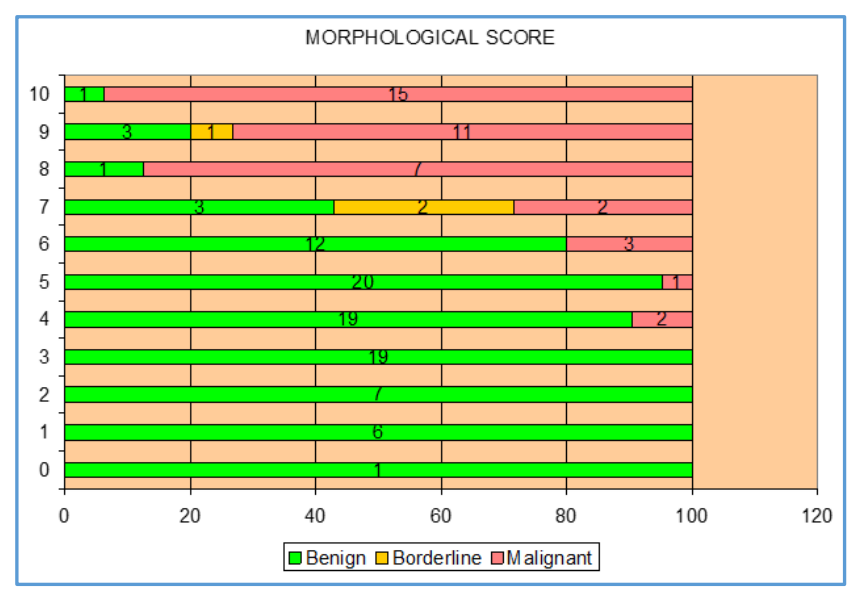

\begin{tabular}{|c|c|c|c|c|c|c|c|}
\hline \multirow{2}{*}{$\begin{array}{c}\text { USG Total } \\
\text { Morphological }\end{array}$} & \multirow{2}{*}{$\begin{array}{c}\text { No. } \\
\text { of } \\
\text { Score }\end{array}$} & \multicolumn{6}{|c|}{ Number } \\
\cline { 3 - 8 } & & \multicolumn{2}{|c|}{ Benign } & \multicolumn{2}{|c|}{$\begin{array}{c}\text { Border } \\
\text { Line }\end{array}$} & \multicolumn{2}{c|}{ Malignant } \\
\cline { 3 - 8 } & No. & $\%$ & No. & $\%$ & No. & $\%$ \\
\hline $0-4$ (Benign) & 54 & 52 & 96.2 & - & - & 2 & 3.73 \\
\hline $\begin{array}{c}5-10 \\
\text { (Malignant) }\end{array}$ & 82 & 40 & 48.8 & 3 & 3.7 & 39 & 47.6 \\
\hline Results as per USG Total Morphological Score and HPE \\
\hline
\end{tabular}

\begin{tabular}{|c|c|c|c|c|c|}
\hline \multirow{2}{*}{$\begin{array}{c}\text { Results as per } \\
\text { Morphological }\end{array}$} & \multirow{2}{*}{$\begin{array}{l}\text { No. of } \\
\text { Score }\end{array}$} & & \multicolumn{4}{|c|}{ Result as per HPE } \\
\cline { 3 - 6 } & & \multicolumn{2}{|c|}{ Positive } & \multicolumn{2}{|c|}{ Negative } \\
\cline { 3 - 6 } & No. & \% & No. & $\%$ \\
\hline Positive (Score > 5) & 82 & 42 & 51.2 & 41 & 48.8 \\
\hline $\begin{array}{c}\text { Negative } \\
\text { (Score < 5) }\end{array}$ & 54 & 40 & 48.8 & 3 & 3.7 \\
\hline Results as per USG Total Morphological Score and HPE \\
\hline
\end{tabular}

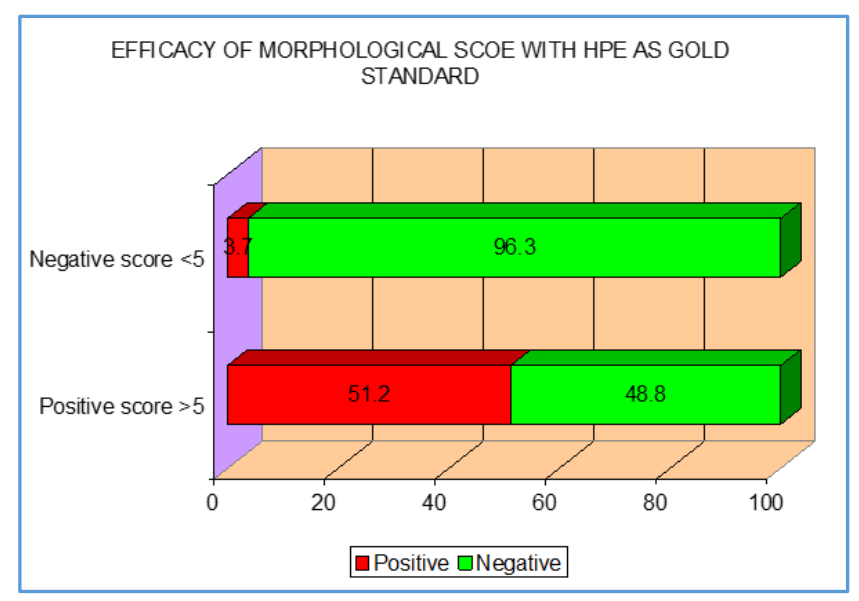

In the present study, epithelial tumours (117) were most common ovarian tumours followed by germ cell tumours (11). In the present study, the morphological index score of $\geq 5$ as a predictor of malignancy has statistical parameters as follows:

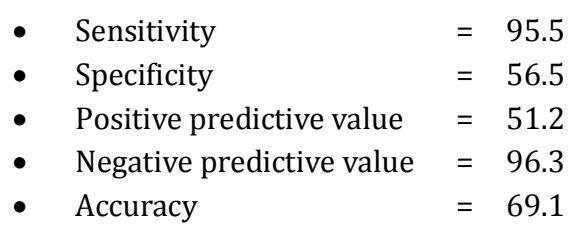

\section{DISCUSSION}

Ovarian tumours manifest a wide spectrum of clinical, morphological and histological features. Clinically, they may be misdiagnosed for other non-neoplastic conditions. In this study, we have analysed 136 ovarian tumours and correlated their clinical presentation and sonographic finding with the histopathology. Of the 136 ovarian tumours, according to histologic diagnosis 91 (66.91\%) of ovarian tumours were benign and 42 (30.9\%) were malignant including 3 (2.2\%) borderline tumour masses. ${ }^{4}$ Ovarian cancer may occur at any age. In our study, the age incidence was between 13 years and 85 years. The peak incidence of benign tumour was between the age group of 21-30 years (35.2\%). Borderline tumours were commonly seen in 45-50 years with a mean age of 49.7 years. Malignant tumours were commonly seen between the age group of 51-60 years with a mean age of 48 years. Ovarian tumours were common in $2^{\text {nd }}$ parity. ${ }^{5}$ of the benign tumours, $33 \%$ were in $2^{\text {nd }}$ parity. Of the malignant tumours, $35.7 \%$ were in $4^{\text {th }}$ parity and above. In the present study, we have reported 5 cases of ovarian tumours during pregnancy and all were benign tumours. ${ }^{6}$ The commonest presenting symptom was pain abdomen (83.1\%) in both benign and malignant tumours. ${ }^{7} 27.2 \%$ of patients presented with mass per abdomen. 10 cases $(7.4 \%)$ presented with menstrual disturbances and 1 case $(0.7 \%)$ with postmenopausal bleeding. The ovarian tumours vary from cystic to solid in consistency. ${ }^{8}$ In the present study $92.3 \%$ of benign tumours were cystic, $40.5 \%$ of malignant tumours were hard and $23.8 \%$ of malignant tumours were variable in consistency. Ovarian tumours may be unilateral or bilateral; bilaterality represents the multicentric origin of the tumour. $6.6 \%$ of benign tumours were bilateral and $45.2 \%$ of malignant tumours were bilateral. ${ }^{9}$ Surface epithelial tumours are common tumours comprising $85.8 \%$ of all ovarian tumours. Among epithelial tumours, serous tumours $(54.5 \%)$ were most common followed by mucinous tumours (22.7\%). 53 (39\%) cases were serous cystadenomas and 19 malignant serous tumours were present.10 There were 21 mucinous cyst adenomas and 8 cases of mucinous cyst adenocarcinoma. Germ cell tumours are the second most common group of tumours. In germ cell tumours, mature benign cystic teratomas (Dermoid cyst) $(7.4 \%)$ were most common. ${ }^{11} 2$ cases of granulosa cell tumour presented with menstrual disturbances and both were malignant. 4 cases of fibrothecoma were present. ${ }^{12}$ With the demand for Evidence Based Medicine, it has become a challenging task to develop a morphological index to predict the malignancy of ovarian mass without any surgical intervention. An ideal scoring system must help in triaging the women with malignancy to an oncologist and avoid unwanted surgical intervention in women with benign tumours. The benign tumours have a mean volume score of 3.58 and the malignant ovarian tumours have a mean volume score of 4.45 . Benign tumours had a mean structural score of 0.7 and malignant tumours had a mean structural score of 3.88. The benign tumours had a morphological score of 4.25 and malignant tumours had a morphological of 8.5 . The malignancy risk is directly related to the volume of the tumour and the various structural components. 13 


\section{CONCLUSION}

Morphological scoring system is helpful in identifying women with ovarian tumours who are at risk for malignancy. Morphological scoring system also effectively decreases the need for unwanted surgery in benign ovarian tumour. It is easy to perform. This scoring system is subjected to interobserver variation. Morphologic indexing helps to standardise the ultrasound reading without adding costs.

\section{REFERENCES}

[1] Schorge J, Schaffer J, Halvorson L, et al. Williams gynecology. $1^{\text {st }}$ edn. New York: McGraw-Hill Companies 2008:716-53.

[2] Ueland FR, DePriest PD, Pavlik EJ, et al. Preoperative differentiation of malignant from benign ovarian tumors: the efficacy of morphology indexing and Doppler flow sonography. Gynecol Oncol 2003;91(1):46-50.

[3] Fleischer AC, Rodgers WH, Kepple DM. Color Doppler sonography of ovarian masses: a multiparameter analysis. J Ultrasound Med 1993;12(1):41-8.

[4] Couto F, Nadkarni NS, Rebellow MJ. Ovarian tumors in Goa: a clinic-pathological study. J Obstet Gynecol India 1993;43(3):408-12.

[5] Rashid S, Sarwar G, Ali A. A clinicopathological study of ovarian cancer in departments of radiotherapy and oncology, Sir Ganga Ram Hospital and Mayo hospital. Lahore 1998;13(4):117-25.
[6] Bakhidze EV. Ovarian tumours associated with pregnancy. Journal of Clinical Oncology 2006;24(18 Suppl):15063.

[7] Malpani AN, Bhattacharya MS, Neuruukar N. Giant ovarian tumor. J Obstet Gynecol India 1989;39(2):2646.

[8] Granberg S, Wikland M, Janson I. Macroscopic characterization of ovarian tumors and the relation to the histological diagnosis: criteria to be used for ultrasound evaluation. Gynecol Oncol 1989;35(2):13944.

[9] Lerner JP, Timor-Tritsch IE, Federman A. Transvaginal ultrasonographic characterization of ovarian masses with an improved, weighted scoring system. Am J Obstet Gynecol 1994;170(1 Pt 1):81-5.

[10] Swamy GG, Satyanarayana N. Clinicopathological analysis of ovarian tumours --a study on five years samples. Nepal Med Coll J 2010;12(4):221-3.

[11] Gobel U, Schneider DT, Calaminus G. Germ-cell tumors in childhood and adolescence. Annals of Oncology 2000;11(3):263-71.

[12] Chen VW, Ruiz B, Killeen JL, et al. Pathology and classification of ovarian tumors. Cancer 2003;97(10 Suppl):2631-42.

[13] Williams PL, Dyson M. Gray's anatomy. 37th edn. London: Churchill Livingstone 1993. 